\title{
Research on Ubiquitous Learning Platform Based on Intelligent Mobile Terminal
}

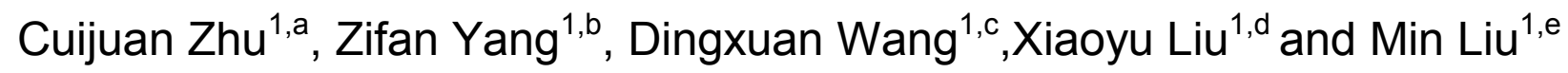 \\ ${ }^{1}$ College of Automobile \& Architectural Engineering, Beihua University, China

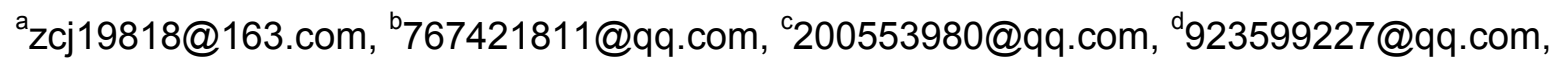 \\ e2632594364@qq.com
}

Keywords: Mobile terminal; Teaching mode; Learning platform; Ubiquitous learning

\begin{abstract}
Ubiquitous learning gives way to learners to obtain the required materials freely at the right time and the proper place. In recent years, with the continuous development of ubiquitous computing technology, and the emergence of various types of computing devices, ubiquitous learning has been rapid development. This paper analyzes the necessity of ubiquitous learning platform construction. On this basis, the ubiquitous learning environment is analyzed, and the overall framework of the learning platform is designed, the functional modules are developed. Study of ubiquitous platform achieve "the classroom + network + mobile" learning model, which provides a completely open, independent learning platform for students, guides significance to the reform of educational model.
\end{abstract}

\section{Introduction}

With the popularity of mobile networks, the functionality of the computer extends to the mobile terminal, Intelligent terminal links deeply each part of work and life .People use intelligent mobile terminal equipment to learn to charge, search for information, browse the web, shopping and so on. In 2016 "China Internet Development Statistics Report" shows, as of December 2015, China's Internet users reached 688 million, Internet penetration rate of $50.3 \%$; The scale of mobile phone users reached 620 million, Wireless network coverage has improved significantly, internet users Wi-Fi usage reached $91.8 \%$. The phone has been used by more than a desktop computer, which leap to become the largest Internet terminal. At the same time the development of intelligent mobile terminal equipment is the basis of mobile learning, office, more than $74 \%$ of teenagers like to learn with mobile phones, find information, browse information and so on. So Ubiquitous learning as a new mode of learning appear timely, which has become a hot topic in educational technology and research areas[1-3].

\section{The Analysis of the Necessity of Constructing the Ubiquitous Learning Platform}

To Provide Students with More Convenient Learning Ways. Students can access and acquire the information, finish the homework assigned by the teachers, simulate the exercise and take the mock examinations when and where they want through the phone. Through the search, you can query more detailed knowledge points. Students timely and quickly access to teacher courseware or reference through the mobile platform. Ubiquitous learning provides learners with digital learning resources and flexible learning methods[4-5]. It opens up a new path for students to learn, which has profounded historical significance for promoting the development of lifelong learning.

To Assist in Classroom Teaching and Support for Formal Learning. The learning management system functions can be completed and improved from the mobile side through the ubiquitous learning platform. It can compete the basic message interactions and group functions. Teaching interaction can be completed through the voice, pictures and it helps teachers to facilitate the completion of the teaching process.

To Provide a Personalized Approach to Learning. As the development of the Internet, the form of learning becomes more and more diverse, so the learners can select when to learn, where to learn, 
what to learn. And learning progress will be based on their own needs. It can make the students' learning time more flexible, the way to learn more convenient and the content richer.

To Develop a Kind of Information Learning Atmosphere. Through the ubiquitous learning platform of the mobile terminal for learning, students get a sense of superiority which is different from what we get in the traditional learning. It stimulates the students' enthusiasm of self-study, changes the students' learning attitude and promotes the formation of a good learning atmosphere. At the same time, the class interaction and the communication of students will be more frequent, so students will have a more appropriate communication place.

To Provide a Better Teaching and Learning Platform for Teachers and Students. The interactive communication of the mobile terminal's ubiquitous learning platform makes the exchange of teachers and students, students and students more targeted. In order to grasp the learning situation of students in class, this learning platform provides knowledge chapter tests. It is a teaching and learning dialogue platform for teachers and students. If you provide the text which is detected, no matter which subject is, you can use this platform to make timely detection of knowledge points which students have learned in class[6-9]. The platform system will test the results of the correct statistics and judgments automatically to help teachers adjust the progress or structure of classroom teaching. Teachers can understand the dynamic study situation. The platform also records the knowledge points which students are not familiar with. Teachers do not need to spend a lot of time changing the volume and analysis.

Based on the overall analysis and design of the learning platform on the intelligent mobile side

\section{Analysis of Pan-learning Technology Environment Based on Intelligent Mobile}

It is more complex in the mobile terminal of the pan-learning technology environment, but to achieve pan-learning should be supported by three technical environments. Including learning resource support, learning service support, learning equipment and network support. Ubiquitous learning environment model technique is shown in Fig. 1.

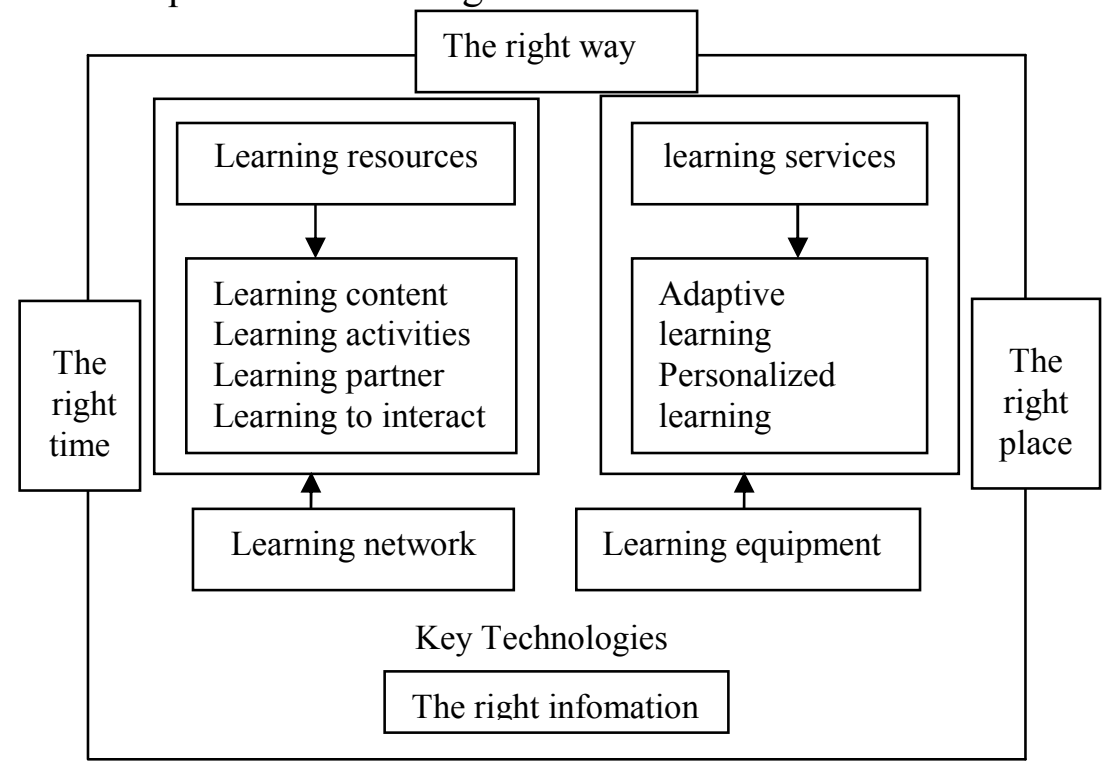

Figure 1. Finite Pan-learning environment model for mobile terminals

Learning Resources. In the pan-learning environment, ubiquitous learning emphasizes that learners can obtain different forms of learning resources, by using a variety of devices, anytime and anywhere, which requires a variety of learning resources in different learning terminals can be a good performance[10]. First, the types of learning resources are varied, for example, can be text documents, pictures, audio, video files and other resources. Second, the learning resources are not only presented in material form, but also through the process of communication and interaction between people. In the pan-learning often appear as learning activities, learning partners and learning to interact. 
Learning Services. Learners in the learning environment in the face of complex learning resources, in improving the efficiency of learning students should ensure that the quality of learning services. The learning support service system in the learning technology environment provides learners with sundry, timely, and plentiful support services. These learning services include intelligent learning services, distance education services; education resources supply services, education, integrated services, and other models. In the process of learning, should be the use of relevant norms and standards for learning services management and monitoring, so as to provide learners who participate in the pan-learning with good personalized services and adaptive services.

Learning Terminal Equipment. The learning terminal is mainly used to provide learners with learning resources and to perceive and respond to learners' necessary operations on learning resources. It has the ability to network access and human-computer interaction interface. Mainly with easy to carry, shape and other characteristics. Currently the ubiquitous learning terminal widely used mainly by MP3, MP4, digital learning machine, intelligent phones, computers and so on. In general, these devices are relatively small, easy to be carried by the learner, and have a certain data storage capacity, these features for learners to provide the basis for learning.

\section{Based on the Overall Analysis and Design of the Learning Platform on the Intelligent Mobile Side}

The Architecture Design of the Mobile Terminal's Generic Learning Platform. The generic learning platform based on mobile terminal mainly has two parts: It has the interface of mobile learning for learners to learn. At the mobile terminal interface, users can get learning courses, communicate with teachers and classmates about the learning, provide feedback for the administrator, and come up with the improvement suggestion in the BBS, etc; In the interface of client management, the teacher can answer the questions of learners and release new learning content at the same time. The administrator can manage the learner's information through the client and review the legitimacy of the posts published by learners in the BBS, etc. The architecture of the learning platform is shown in Fig. 2 .

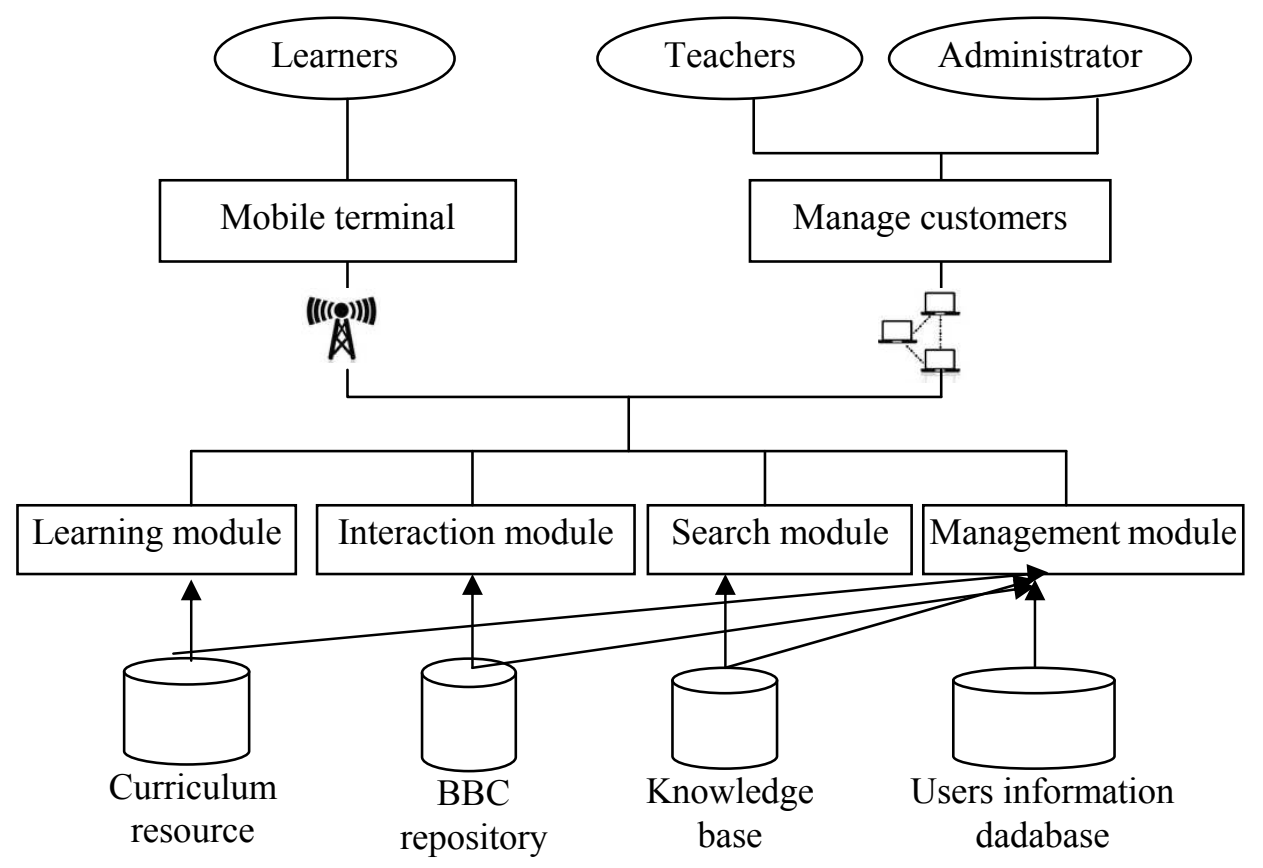

Figure 2. Finite The architecture of the mobile terminal's generic learning platform

The Functional Architecture Design of Mobile Terminals in Generic Learning Platform. This is a mobile learning platform that processes data through a mobile terminal device. This project is chosen operating system based on the Linux kernel Android as the mobile terminal system. It develops the application program and implants it into the operating system to realize the function of 
mobile learning. The learning platform generally adopts the combination of theory and implementation, uses the method that theory guides the engineering design and the principle of modular design to make combination of software and hardware, and have continuous improvement. The main function of the system is for the learners to access learning courses through mobile terminal, for the teachers to interact with learners through the platform and for administrators to manage user data of learners and teachers via a browse. The functional architecture of the mobile terminal's generic learning system is shown in Fig. 3 .

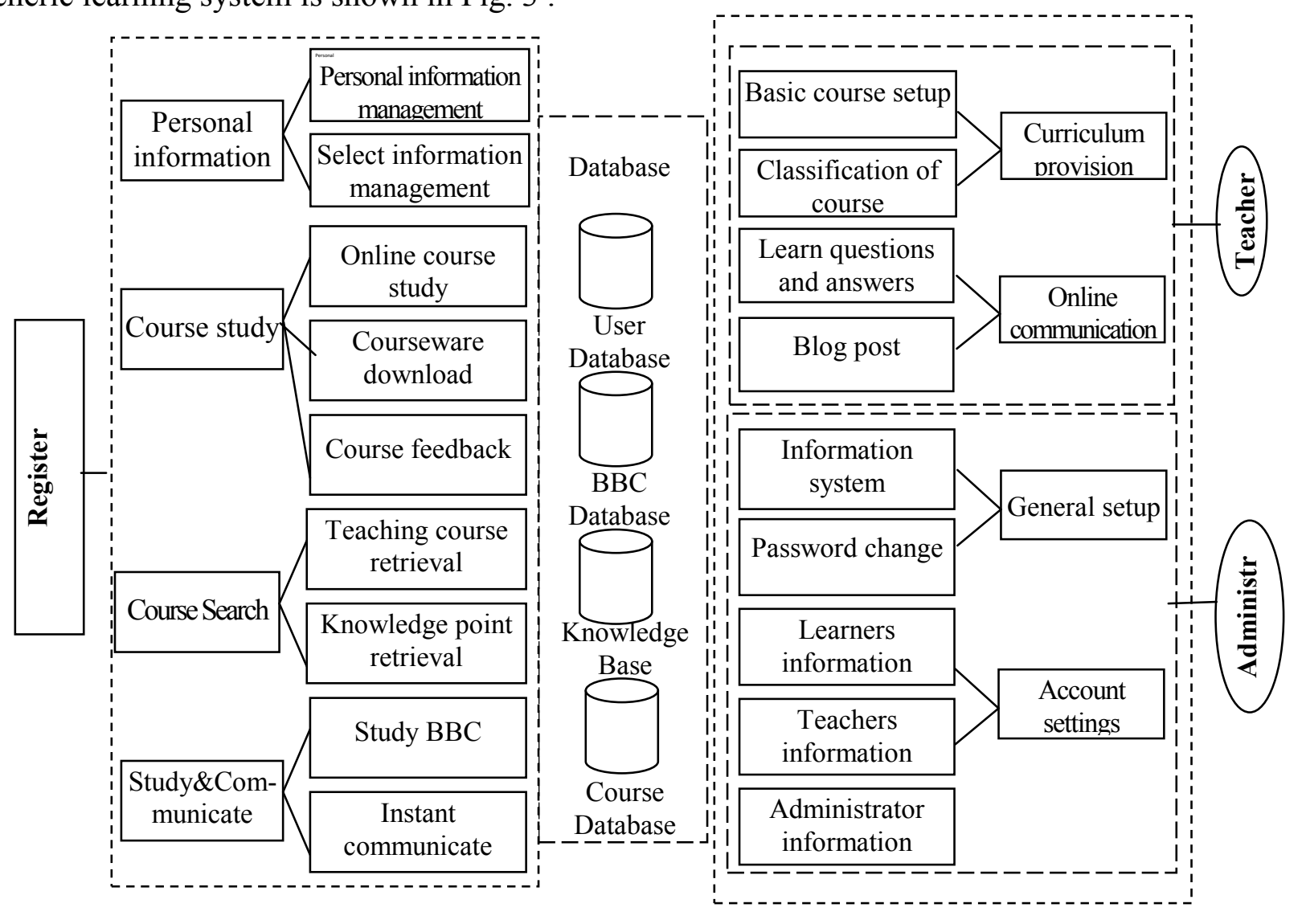

Figure 3. Finite The functional architecture of the mobile terminal's generic learning

\section{Summary}

The construction of the ubiquitous learning platform fully embodies the role of students as the main body, which Cultivate students' habit of learning independently and Enhance the students' self-confidence, it is beneficial to improve innovative thinking competency. The platform has changed the traditional teaching deficiencies, through this platform which can inspire students' diligent thinking, participate actively. To study platform is helpful to improve and produce great results. According to the characteristics of each student in accordance with their aptitude, the platform is also conducive to the teacher at any time to master the situation of students. In short, the development of the learning platform is conducive to the realization of teaching reform and the development of logistics management professional.

\section{Acknowledgements}

School-level teaching and research projects (XJYB2016008)

\section{References}

[1] Strayer, F.J: Learning Environment Research, Vol. 15 (2012) No.2, p.171. 
[2] Murakami, G.T: Nomura Research Institute Papers, Vol. 20 (2003) No.3, p.66.

[3] Y. Liu and Y. Luo: Journal of Mudanjiang University, Vol. 25 (2016) No.7, p.172.(In Chinese)

[4] Yang, S.J.H: Journal of Educational Technology and Society, Vol. 9 (2006) No.1, p.188.

[5] University of Sussex on http://www.sussex.ac.uk.

[6] G. Li: Crazy Android handouts (Electronic Industry Press, Switzerland 2013)

[7] J.H.Xu: Journal of Nanning Polytechnic, Vol. 20 (2015) No.1,p.59. (In Chinese)

[8] F.Y. Xu: Journal of Jilin Radio and TV University, Vol. 164 (2015) No.8, p.22. (In Chinese)

[9] F.X. Bai: Journal of Yunnan University, Vol. 36 (2014) No.8, p.145. (In Chinese)

[10] Y.F. Lin: Journal of Ningbo University, Vol. 35 (2013) No.1, p.106. (In Chinese) 